OPEN ACCESS

Edited by: Alessio Merola, Magna Græcia University, Italy

Reviewed by: Roslyn Watson Livingstone, Sunny Hill Health Centre for Children, Canada Carole W. Dennis, Ithaca College, USA

*Correspondence:

Samuel W. Logan sam.logan@oregonstate.edu

Specialty section: This article was submitted to Biomedical Robotics,

a section of the journal Frontiers in Robotics and $A$ I

Received: 08 August 2016 Accepted: 09 February 2017 Published: 02 March 2017

Citation: Logan SW, Feldner HA, Bogart KR, Goodwin B, Ross SM, Catena MA, Whitesell AA, Sefton ZJ, Smart WD and Galloway JC (2017) Toy-Based Technologies for

Children with Disabilities

Simultaneously Supporting Self-Directed Mobility, Participation, and Function: A Tech Report.

Front. Robot. Al 4:7. doi: 10.3389/frobt.2017.00007

\section{Toy-Based Technologies for Children with Disabilities Simultaneously Supporting Self- Directed Mobility, Participation, and Function: A Tech Report}

\author{
Samuel W. Logan ${ }^{1 *}$, Heather Ann Feldner', Kathleen R. Bogart', Brianna Goodwin', \\ Samantha M. Ross', Michele Ann Catena', Austin A. Whitesell', Zachary J. Sefton', \\ William D. Smart ${ }^{1}$ and James Cole Galloway ${ }^{3}$ \\ ${ }^{1}$ Oregon State University, Corvallis, OR, USA, ${ }^{2}$ University of Washington, Seattle, WA, USA, ${ }^{3}$ University of Delaware, \\ Newark, DE, USA
}

Go Baby Go is a community-based outreach, research, and clinical treatment program that works with families, clinicians, service providers, and industry to provide pediatric equipment to children with disabilities for movement, mobility, and socialization. The purpose of the current technical report is to describe two innovative and novel extensions of the initial modified ride-on car technology that encourages self-directed mobility, participation, and function for young children with disabilities. The current report provides a description of the "sit-to-stand" and "throw-baby-throw" ride-on car technologies: (1) Sit-to-stand modified ride-on car technology: commercially available, battery-operated, ride-on cars are adapted by installing a large, easy-to-press activation switch that is placed on the steering wheel. The switch has a large surface area and turns on at the slightest touch allowing easier activation for children with disabilities. Common materials such as PVC pipe, swimming kickboards and fun noodles, and Velcro are used to build a custom seating system that provides optimum support for each child. There are no commercially available powered wheelchairs for children with disabilities from birth to 3 years old. An innovative sit-to-stand version of modified ride-on car will be presented and requires a child to stand up in order to activate the switch to encourage the physical skills of pulling from sit-to-stand, weight bearing, and balance; (2) Throw-baby-throw technology: children with disabilities that experience limited upper-extremity function are not able to throw an object. The throw-baby-throw technology includes modification of a commercially available, toy-based ball pitching machine that projects foam balls. We modified the toy so that it is switch activated and attached to a modified ride-on car. Our modified throwing device allows children with disabilities to engage in the fundamental motor skill of throwing. Both technologies presented in this technical report embrace the holistic view of the International Classification of Functioning, Disability, and Health framework by placing equal emphasis on the body structure and function, activity, and 
participation domains. Both technologies specifically target the advancement of physical skills while simultaneously providing opportunities to engage in experiences associated with activity and participation.

Keywords: mobility, children, do-it-yourself, medical technology devices, rehabilitation

\section{INTRODUCTION}

Self-directed mobility is a fundamental human right, especially for young children with disabilities who rely on adults to provide them access to mobility experiences. Self-directed mobility is defined as movement that is initiated by an individual and may include independent locomotion such as walking, the use of mobility technology such as gait trainers, standers, or the use of powered mobility devices including motorized wheelchairs, battery-operated ride-on toy cars, or other similar devices. Children without disabilities experience developmental gains in cognition, language, and social skills as a result of the onset of independent locomotion that occurs between 10 and 14 months of age (Campos et al., 2000; Uchiyama et al., 2008; Anderson et al., 2013).

Regardless of ability, the grounded cognition framework (aka embodied cognition or embodied development) (Thelen and Smith, 1994; Thelen et al., 2001; Smith and Gasser, 2005) suggests that learning occurs through movement as bodies and minds interact with and within environments and experiences of particular cultural or social contexts (Lobo et al., 2013). Research in developmental psychology and pediatric rehabilitation demonstrates that active (i.e., self-directed) movement experiences are fundamentally different and more advantageous compared to passive movement experiences (Held and Hein, 1963; Libertus and Needham, 2010; Jones et al., 2012; Lobo et al., 2013). Thus, the relatively passive lives of young children with disabilities who experience limited mobility are especially disturbing.

Over 30 years of research has demonstrated that young children with disabilities who experience the most severe delays in mobility can use powered mobility devices for self-directed mobility (Butler et al., 1983; Galloway et al., 2008; Lynch et al., 2009; Livingstone, 2010; Ragonesi et al., 2010; Jones et al., 2012). Equally important, using this technology results in some of the developmental gains associated with the onset of crawling and walking (Butler et al., 1983; Galloway et al., 2008; Lynch et al., 2009; Livingstone, 2010; Ragonesi et al., 2010; Jones et al., 2012). Unfortunately, the reality is that many if not most of the children who could benefit from powered mobility do not gain access to this technology until after 5 years of age (Nicholson and Bonsall, 2002). Given the importance of self-directed mobility, we believe that this lack of access is nothing less than a form of human rights violation - but a violation that is readily eliminated as the barriers to access and solutions are both known and being addressed by our work and others (Feldner et al., 2016).

One significant barrier that prevents widespread acceptance of access to self-directed mobility experiences is the absence of commercially available powered mobility devices that are specifically designed for young children with disabilities and accessible to all. For example, the Wizzybug@ manufactured by designability@ is commercially available but is not available for purchase in North America. Another example is the Skippi@ manufactured by Ottobock $\odot$ but starts at a base price of $\$ 10,000$. Furthermore, the cost of other available powered mobility devices can be up to $\$ 30,000$ or more (Cooper et al., 2008). Insurance companies routinely deny funding requests based on cost, environmental accessibility, or a child's young age (Nicholson and Bonsall, 2002; Staincliffe, 2003). Modifying off-the-shelf, battery-operated ride-on cars has emerged as an alternative to traditional powered mobility devices (Huang and Galloway, 2012; Logan et al., 2014, 2016).

Go Baby Go is a community-based outreach, research, and clinical treatment program that works with families, clinicians, service providers, and industry to provide pediatric equipment to children with disabilities for movement, mobility, and socialization. The modified ride-on car technology, which was explored intermittently in the late 1980s and early 1990s, re-emerged from the Go Baby Go program in 2012 (Chiulli et al., 1988; Cooper et al., 1992). Commercially available, battery-operated, ride-on cars are adapted by installing a large, accessible activation switch. Common materials such as PVC pipe, swimming kickboards, and Velcro are used to build a customized seating system for support. Modified ride-on cars offer a low-cost, powered mobility device that is affordable, accessible, and fun. Because the device is a mainstream toy, caregivers and clinicians can address child and family goals without the social stigma of a medical device (Gibson et al., 2012). Not surprisingly, evidence is emerging that suggests positive developmental gains for children with disabilities who use modified ride-on cars for self-directed mobility (Huang and Galloway, 2012; Logan et al., 2014, 2016).

The purpose of the current technical report is to describe two innovative and novel extensions of the initial modified ride-on car technology that encourages self-directed mobility, participation, and function for young children with disabilities. The general features, modifications, and clinical applications of the modified ride-on car technology are described in a previously published technical report (Huang and Galloway, 2012). One major feature of the initial modified ride-on car technology is that the activation switch is pressed while a child is seated. A child must use their hand, trunk, or head in order to press the activation switch (see Figure 1). The current report extends that work to describe "sit-to-stand" and "throw-baby-throw" ride-on car technologies.

\section{SIT-TO-STAND MODIFIED RIDE-ON CAR TECHNOLOGY}

\section{Scientific Background}

Young children who experience mobility delays often experience delays across developmental domains (Schoenmakers et al., 2005; 
Webster and Carter, 2007; Wuang et al., 2008; Carter et al., 2010). For example, young children who experience Down syndrome often will ultimately sit, stand, and walk up to a year or later than peers without disabilities (Tudella et al., 2011). These delays seriously restrict their interaction with family and friends, and their general development (Fidler, 2005). Ulrich and colleagues' pioneering work on treadmill training suggests that if training is started early, is meaningful to the infant, is systematically progressed, and is family centered, then physical skills, such as walking, of young children who experience Down syndrome can be advanced (Ulrich et al., 2001; Wu et al., 2010). For example, with less than 10 min of treadmill stepping per day for 6 months, young children who experience Down syndrome walked more than 100 days earlier than controls who received only standard care (Ulrich et al., 2001). Because treadmills are typically stationary and inside, children cannot use them to socialize through play with mobile peers in either indoor or outdoor environments. Sit-to-stand modified ride-on cars have the potential to be incorporated in daily experiences of children and provide opportunities to gain physical skills (balance, strength, coordination), functional skills (standing, sit-to-stand transition), and participation skills (use of car with peers for play).

The sit-to-stand technology is an innovative and novel treatment option that can be used in a variety of real-world settings. A multisite study of the impact of this technology will be completed within the year; however, previously published pilot work suggests that caregivers and clinicians should expect gains from daily use. For example, a recent case report found that a 4-year old that experiences a mobility disability engaged in more play behaviors with peers while using a sit-to-stand modified ride-on

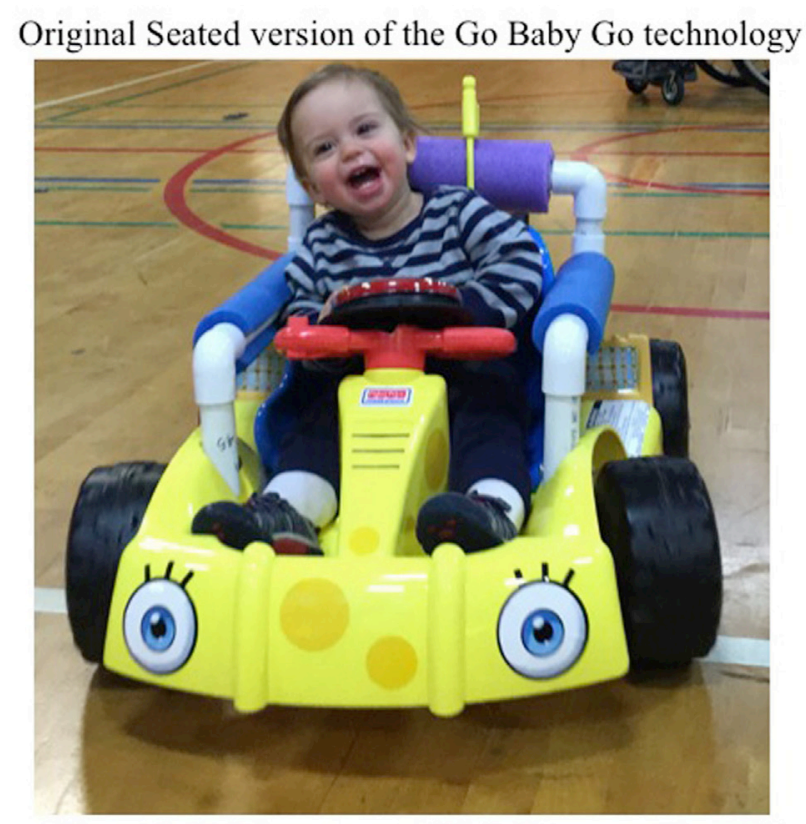

FIGURE 1 | Child uses a modified ride-on car for self-directed mobility, exploration, and play. The car is activated by pressing the center activation switch. car compared to using forearm crutches (Logan et al., 2017). This case is especially instructive as this child walked with crutches and would be considered very high functioning for a child who experiences mobility impairments. Yet, in important educational environments larger than the classroom-such as gymnasium and playground-his mobility and socialization were significantly limited and these limitations were lessened with use of a modified ride-on car. Group studies are underway and will provide a more detailed understanding of the physiological and psychosocial benefits of daily sit-to-stand use of modified ride-on cars.

\section{Technical Background}

The philosophy behind Go Baby Go technology is to provide safe yet speedy access to important mobility technology that can be purchased or built by every family and clinician planet wide. As such, the sit-to-stand technology includes modification of off-the-shelf, battery-operated, ride-on cars [see Table $\mathbf{1}$ for a description of available $6 \mathrm{~V}$, all-terrain vehicle (ATV) style rideon cars]. Below we describe a common modification package. ${ }^{1}$

The ATV style ride-on car typically comes with a pre-installed activation switch that is located on the handlebars and used for the seated mode. The switch contacts are normally open, which means that the switch has to be pressed in order to activate. Modified drive system: a SparkFun@ Big Dome momentary push button (\$9.95; product ID: 11274 ) was installed on top of the seat and used for the standing mode. The switch circuit configuration is "normally closed," which means that pressure on the switch has to be released in order to activate. Thus, a child must pull him or herself from sit-to-stand, thereby activating the switch (see Figure 2 for description of switch wiring of seated and standing modes). Installation on top of the seat allows for easy adjustment

\footnotetext{
${ }^{1}$ This modification description is for demonstration purposes. We suggest modifications be inspected by an engineering expert.
}

TABLE 1 | Description of available 6 V, all-terrain vehicle (ATV) style rideon cars.

\begin{tabular}{|c|c|c|}
\hline & Fisher-Price $\odot$ Lil' Quad & Kid Trax@ \\
\hline Availability & $\begin{array}{l}\text { Amazon, Toys R Us, Wal- } \\
\text { Mart, other retailers }\end{array}$ & $\begin{array}{l}\text { Target, Toys R Us, Wal-Mart, } \\
\text { other retailers }\end{array}$ \\
\hline Cost & $\$ 65$ and up & $\$ 55$ and up \\
\hline Age, years & $1-3$ & $1.5+$ \\
\hline Weight, lbs. & 40 & $35-45$ \\
\hline $\begin{array}{l}\text { Speed, miles per } \\
\text { hour }\end{array}$ & 2 & 1.5 \\
\hline Seating capacity & 1 & 1 \\
\hline Wheels & 4 & 4 \\
\hline Terrain & Hard surfaces, grass & Hard surfaces, grass \\
\hline Styles & Trains, ATVs, farm vehicles & ATVs \\
\hline $\begin{array}{l}\text { Designs/frame } \\
\text { options }\end{array}$ & $\begin{array}{l}\text { Colorful, cartoon characters } \\
\text { with plastic frame }\end{array}$ & $\begin{array}{l}\text { Colorful, cartoon characters } \\
\text { with plastic frame }\end{array}$ \\
\hline Battery/drive & $6 \mathrm{~V} /$ single gearbox & $6 \mathrm{~V} /$ single gearbox \\
\hline Noise level & Minimally distracting & Minimally distracting \\
\hline Activation & Push button & Push button \\
\hline Transportation & Any type of car & Any type of car \\
\hline Maintenance & $\begin{array}{l}\text { Keep clean, regularly check } \\
\text { battery power }\end{array}$ & $\begin{array}{l}\text { Keep clean, keep dry, store } \\
\text { away from stoves and heaters }\end{array}$ \\
\hline
\end{tabular}

Information gathered from manufacturers and/or distribution websites. 
Switch Wiring of Seated and Standing Modes

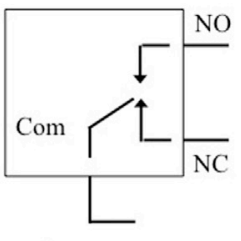

A

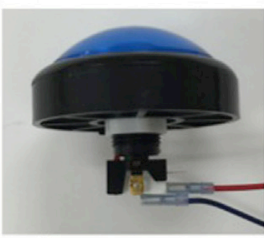

B

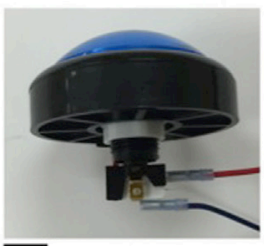

c

FIGURE 2 | (A) Electrical diagram of the switch used for the standing mode. $\mathrm{NO}=$ normally open; $\mathrm{NC}=$ normally closed; (B) SparkFun@ Big Dome push-button switch wired for use of seated mode; (C) SparkFun@ Big Dome push-button switch wired for use of standing mode.

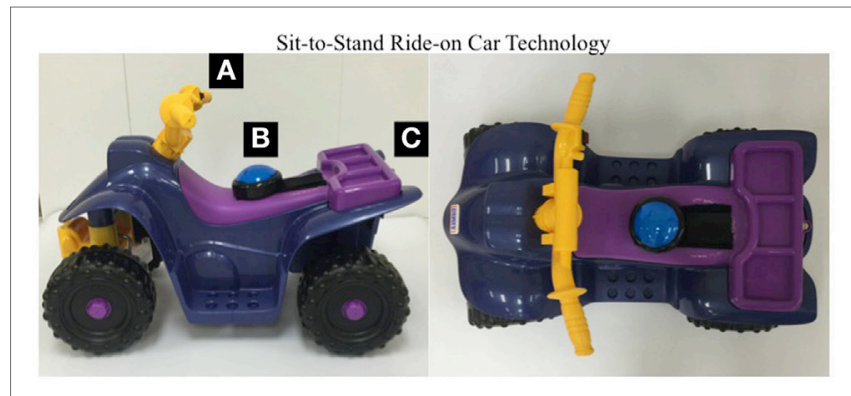

FIGURE 3 | (A) Pre-installed activation switch that can be used while a child is seated. (B) Big Dome button installed on the seat. A child must pull itself from sit-to-stand in order to release the switch and activate the car.

(C) Toggle switch (out of view) installed on the back of the ride-on car and allows choice between seated or standing mode, and an off switch. of switch placement along the length of the seat. This is important because the switch location can be moved as a child grows or if multiple children use the modified ride-on car in a clinical setting (see Figure 3 for modified sit-to stand ride-on car).

A major feature of the electrical modification is installation of a "double-pole, double-throw" (DPDT) toggle switch. The seated and standing mode switches are interfaced with the DPDT toggle switch. This allows for the modified ride-on car to be used in either the seated or standing mode. The DPDT toggle switch also provides an "off" setting that prevents unwanted use of the modified ride-on car, including for safe transfers in and out of the ride-on car (see Figure $\mathbf{4}$ for description of toggle switch installation).

Seating and support system: the seating and support system for the sit-to-stand technology is very similar to the seated car versions (Huang and Galloway, 2012). However, different types of modifications are needed that provide additional support while a child is in the standing position. Low-cost and readily accessible PVC pipe and connectors were used to fabricate back and lateral support. Then, industrial strength Velcro was used to provide lateral support (see Figure 5 for seating and support system examples).

\section{THROW-BABY-THROW TECHNOLOGY}

\section{Scientific Background}

An individual's overall capability to perform a variety of skills and tasks related to the motor domain (aka motor competence) is related to positive developmental trajectories of health including physical activity, health-related fitness, perceived competence, and weight status (Robinson et al., 2015). One aspect of motor competence includes fundamental motor skills. Fundamental motor skills include object control/ball skills (i.e., throwing, catching, etc.), locomotor skills (i.e., running, jumping, etc.), and balance/ stability skills (i.e., one-leg balance, etc.) (Clark and Metcalfe, 2002; Haywood and Getchell, 2009). These skills are considered the "building blocks" of more advanced, complex movements required to participate in sports, games, or other context specific physical activity. Fundamental motor skills, including throwing, are not thought to develop naturally during childhood, but through high-quality teaching, practice, and experience (Logan et al., 2011). Children with disabilities may experience physical or cognitive differences that make it challenging to learn, practice, and develop the skill of throwing; yet deserve equitable access to participate in activities that require throwing to support positive development. Like with ride-on cars, simple modifications can improve the access to these important skills and in turn may continue to encourage positive peer interactions.

The skill of throwing may be modified to provide children with disabilities with opportunities to engage in physical activity similar to children without disabilities. For example, a larger object may be used so that a child is more easily able to grasp and throw. The goal of skill modification is that all children, regardless of ability, can be successful and active participants. However, the modification of a larger ball size, or other modifications, may not be suitable for young children with disabilities who experience severe limitations of arm movement. Thus, fewer strategies exist to modify the skill of throwing for young children with disabilities. This is likely due to their smaller body size, lack of muscle strength and coordination, and greater difficulty in relaying task instructions. These children may experience limited physical movement and are often left out of throwing activities or they are dependent upon adults to help them throw. The throw-babythrow technology is an innovative and novel approach to encourage the physical skill of reaching, while allowing a child to engage in the fundamental motor skill of throwing.

\section{Technical Background}

Throw-baby-throw technology includes modification of off-theshelf, battery-operated, toy-based ball pitching machines. For the current report, we modified the Fisher-Price $\subset$ Triple Hit Baseball model ( $\$ 33.00$, Product B6312). This model requires four D-cell batteries and operates by pressing an activation button on the device that launches four foam balls on a timer. This model uses an internal, spinning wheel (servomotor) to propel foam balls and includes an on/off switch that closes and opens the circuit, respectively. The servomotor rotates and launches the foam ball when the activation switch is pressed. After the launch, the spring 


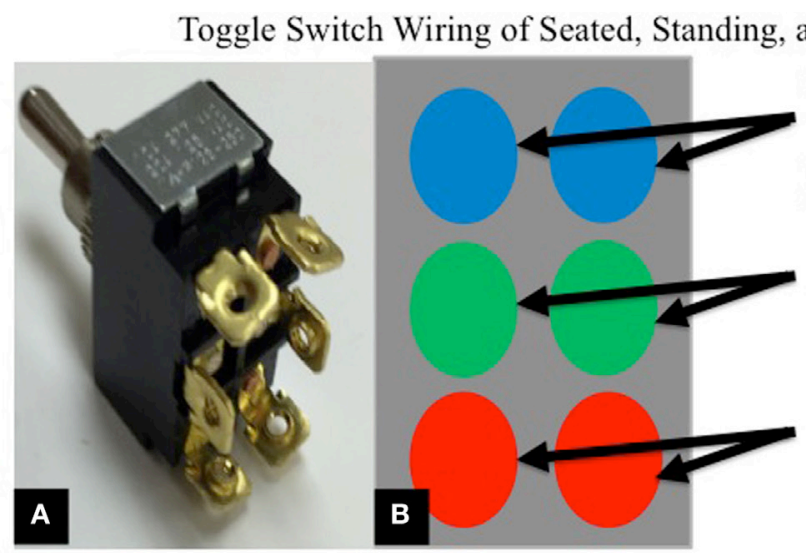

Blue Wires: Connects the toggle switch to the sit-tostand switch installed on the seat of the car.

Green Wires: Connects the toggle switch to the battery and the motor.

Red Wires: Connects toggle switch to the preinstalled activation switch for seated mode located on the handlebars.

FIGURE 4 | (A) Double-pole double-throw toggle switch; (B) electrical diagram that outlines the interface between the toggle switch and the ride-on car. Note: the color of the wires may vary between ride-on car models. The colors displayed were chosen arbitrarily.

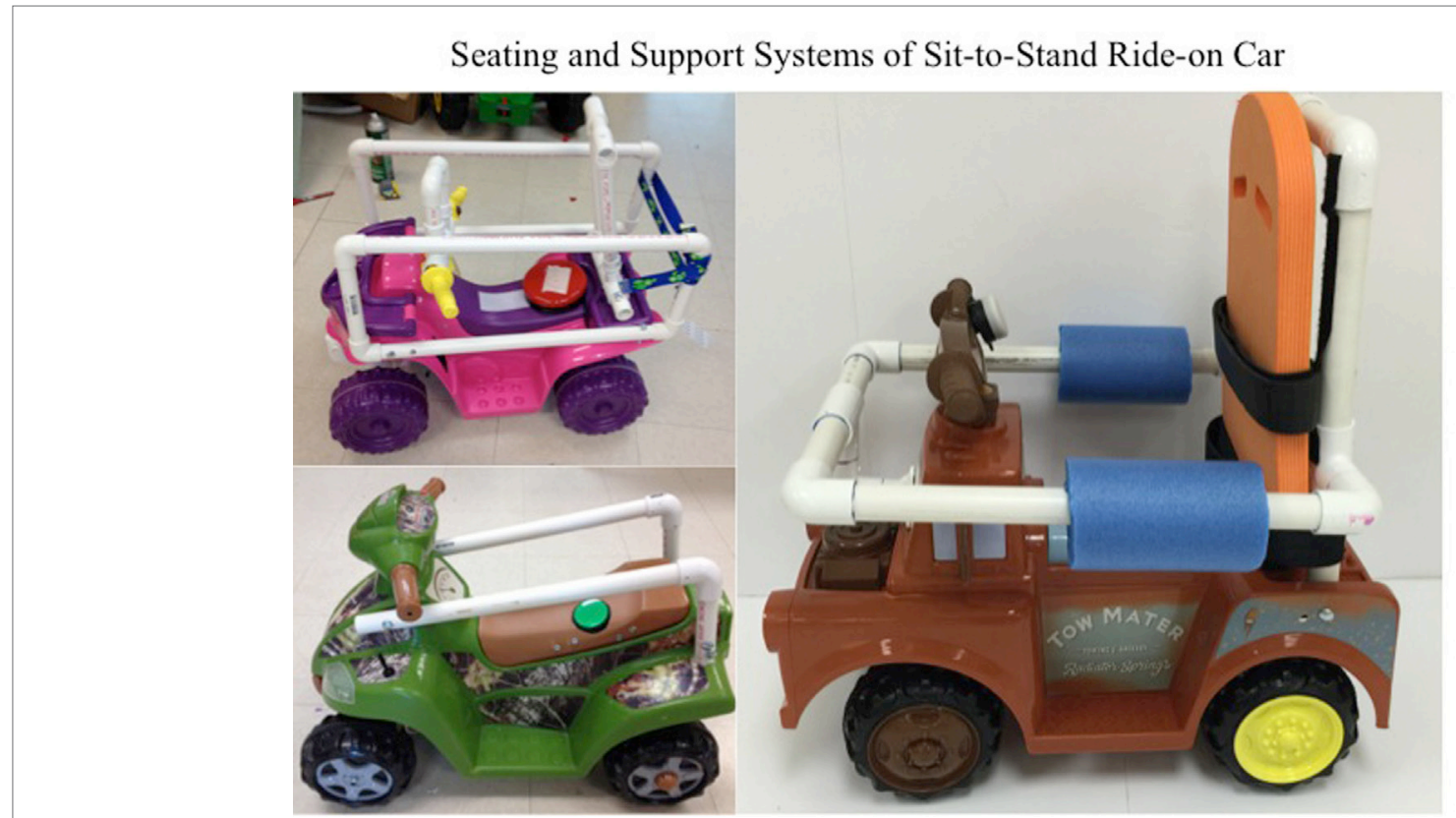

FIGURE 5 | Three examples of seating and support systems that use PVC pipe and connectors, swimming kickboards, pool noodles, and Velcro.

inside the servomotor returns to its initial position (see Table 2 for a description of the Fisher-Price $\subset$ Triple Hit Baseball toypitching machine).

\section{Modified Launch System}

An Adafruit@ large arcade momentary push button (\$9.95, Product 1185) was installed to allow for control of the foam ball launch. This allows for easier activation due to the large surface area of the arcade button and can be placed in a location that is accessible to each child. A potentiometer (i.e., variable resistor) from Digikey ( $\$ 5.34$, Product CT2150-ND) was installed to allow adjustment of the launch speed of the foam ball. The potentiometer is connected in-line with the motor in order to vary the voltage to it, thus varying its maximum speed (see Figure 6 for description of electrical modifications). Mounting system: the Fisher-Price@ Triple Hit Baseball model is attached to the side of the PVC seating and support system of the modified ride-on car via a wood panel and U-bolts. The installed large arcade button and potentiometer are attached to the top of the PVC seating and support system of the modified ride-on car via a separate wood panel and U-bolts (see Figure 7 for a modified ride-on car that includes the throw-baby-throw technology). 
TABLE 2 | Description of the Fisher-Price $\odot$ Triple Hit Baseball toypitching machine.

Fisher-Price $\odot$ Triple Hit Baseball

\section{Availability}

Cost

Age, years

Weight, lbs

Speed, miles per hour

Battery/motor

Noise level

Activation

Transportation

Maintenance

Information gathered from manufacturers and/or distribution websites.

${ }^{a}$ According to the manufacturer, this toy is not suitable for ages under 3 years. It

contains one or more of the following items: marbles, small ball, or small parts. This

recommendation is based upon the assumption that children will use product as a pitching machine.

${ }^{b}$ Measured values.

\section{LIMITATIONS AND ADVANTAGES OF BOTH TECHNOLOGIES}

One limitation includes that modifications range from relatively simple (sit-to-stand technology) to complex (throw-baby-throw technology). It may be difficult for individuals without prior engineering or electrical experience to complete the modifications on their own. Another limitation is the level of noise that ranges from minimally (sit-to-stand technology) to potentially distracting (throw-baby-throw technology). Finally, while families and volunteers can complete the modifications using step-by-step instructions, many people are hesitant to attempt the modifications themselves, citing intimidation, or a lack of perceived confidence in their technical abilities.

A limitation of both technologies is that often, a caregiver still may be required to provide assistance with steering (sitto-stand technology) or helping to retrieve the foam balls (throw-baby-throw technology). However, it is hoped that incorporating the throwing device on to the car will also provide increased opportunities for peer-to-peer interaction in all aspects of ball game play, where a peer might engage in ball retrieval rather than a caregiver. In addition, children with disabilities may not have the coordination and bilateral upper-extremity function to simultaneously use both technologies at the same time. Children with disabilities may need to stop the ride-on car before activating the switch for throwing. However, the skill level required to run and throw at the same time is often beyond the capabilities of young children without disabilities. The throw-baby-throw technology is designed to emphasize social interaction, rather than proficiency of sport. Future research will examine the use of both technologies by children with disabilities in natural contexts such as early learning centers and within the home.

There are several advantages to the sit-to-stand and throwbaby-throw technologies. One advantage is that both technologies were developed using developmentally inspired principles of powered mobility technology (Feldner et al., 2016). These principles include: adaptive, flexible, durable, low-cost, esthetic, and accessible [see Feldner et al. (2016) for a full description of each principle]. Another advantage is that both technologies are designed to be simultaneously "assistive" and "rehabilitative." For example, a wheelchair is an assistive device that supports participation, but typically does not contribute to increasing function. By contrast, a treadmill is a rehabilitative device that supports function, but typically does not contribute to increasing participation. The sit-to-stand technology is assistive as it provides a means of self-directed mobility. This technology is also rehabilitative because embedded within its use is encouragement of the physical skills of pulling from sit-to-stand and dynamic-assisted standing and balance. The throw-baby-throw technology is assistive because it provides a means of throwing. This technology is also rehabilitative because embedded within its use is encouragement of the physical skill of reaching. The activation switch can be moved closer or further away, or on the left/right side or in midline in order to encourage reaching in a way that promotes physical strength and coordination.

Another advantage is that both technologies are lightweight and portable which promotes use within a variety of real-world contexts, such as the home, early childcare center, playground, and other community spaces. Due to this design feature, the technologies may be used much more frequently and for longer durations than traditional pediatric technology. Another advantage is the relatively low-cost of modification supplies that will enable greater access to all families. Finally, these toy-based technologies are inclusive and socially welcoming for children of all abilities, promoting further integration and participation of children with and without disabilities within the same play contexts.

Another advantage of the throw-baby throw technology is that it may foster independence. A majority of switch adapted toys focus on sensory consequences such as lights, sounds, and vibrations, rather than an emphasis on participation that may be provided by the throw-baby-throw technology. Typically, switch adapted toys are simply placed next to a child with a disability. This does not allow a child with a disability to move within the environment to initiate social and play interactions with others. The attachment of the throw-baby-throw technology to a modified ride-on car provides the potential of more independence in participating with others by allowing a child with a disability to make their own decisions with regard to exploring the environment and engaging in the skill of throwing.

\section{DISCUSSION}

Over the past 15 years, pediatric rehabilitation professionals have widely adopted a modern health framework, the World Health Organization's International Classification of Functioning, Disability, and Health (ICF), as a model of holistic practice (World Health Organization, 2001). The ICF includes three health domains: (1) body structure (anatomical parts of the body) and function (physiological functions of body systems); (2) activity (execution of a task or action by an individual); and (3) participation (involvement in life situations). The ICF also considers environmental factors that make up the physical, social, 


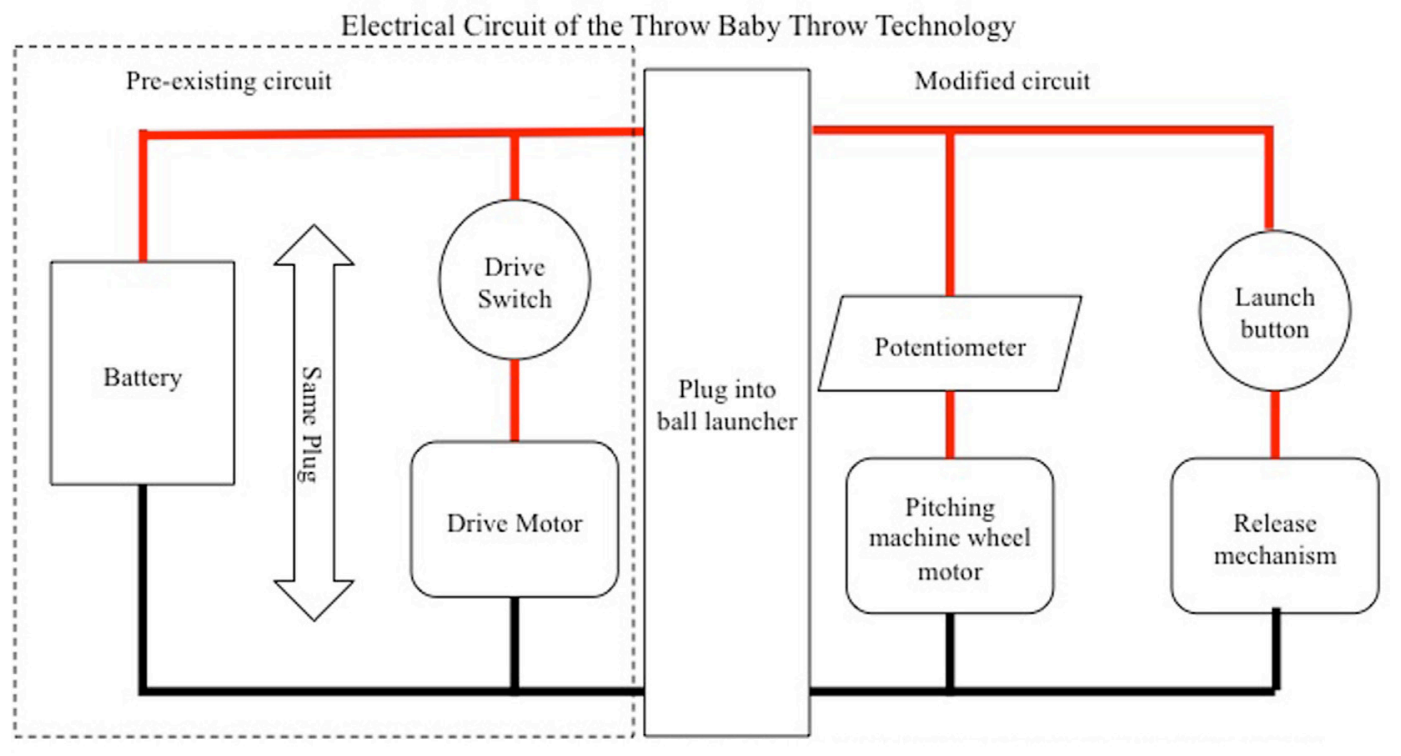

FIGURE 6 | Each thick line represents a separate wire. Red lines indicate high voltage connections, while the black lines indicate ground connections. Each intersection indicates a wire-to-wire connection. The dotted line represents the pre-existing circuit.

and attitudinal environment in which people live and conduct their lives (World Health Organization, 2001).

The ICF was generated out of concern that previous classifications of the various domains of health and functioning neglected to recognize the social and environmental barriers to function that exist external to an individual, thus situating disability as solely an individual problem (Wiart and Darrah, 2002; Ostensjø et al., 2005; Gibson and Teachman, 2012). The ICF model, as a response to these concerns, contains body function and structure domains as well as activity and participation domains, all of which can influence or be influenced by personal factors and environmental contexts, but which are not meant to be linear or to imply causal relationships (Law et al., 2007; Gibson et al., 2009; Gibson and Teachman, 2012).

Despite the adoption of the ICF, the current culture of pediatric rehabilitation and caregivers alike view the use of powered mobility devices as a "last resort," once all other efforts toward the skill of walking have been exhausted (Bottos and Gericke, 2003; Wiart et al., 2004; Rosen et al., 2009; Feldner et al., 2016). This represents a dichotomous view of thinking suggesting that self-directed mobility should be achieved by either a powered mobility device or walking. This dichotomous view may persist, in part, because researchers and caregivers have observed that the inability to walk is considered the most visible signifier of disability (Wiart et al., 2004; Daudji et al., 2011; Gibson and Teachman, 2012). For example, when comparing a walker device to a wheeled mobility device, a caregiver expresses

Especially the kids at school, they think it's pretty neat that he's walking like they are. He seems to be more of a boy than more of a, ah, than you know someone with a disability (McKeever et al., 2013, p. 386).
This view reinforces traditional emphasis on body structure and function goals of the ICF, which focuses on walking as "normalcy," undermining other forms of mobility, and implying that participation is a lesser goal. Moreover, it equates disability with being less than a boy, or, to put it bluntly, less than human. Emerging research indicates that this sentiment is the consequence, in part, of a lack of positive disability narratives that challenge walking as the only means of "normalcy," which, left unmitigated, often results in children with disabilities' internalization of stigma and low self-worth (Gibson et al., 2011; Gibson and Teachman, 2012). Several studies cite the role of rehabilitation professionals as key in either maintaining or challenging these established normative views on disability and walking (Wiart and Darrah, 2002; Bottos and Gericke, 2003; Wiart et al., 2004; Gibson et al., 2011; Gibson and Teachman, 2012).

The sit-to-stand and throw-baby-throw technologies presented in this technical report embrace the holistic view of the ICF by placing equal emphasis on the body structure and function, activity, and participation domains. The sit-to-stand technology specifically targets the physical skills of pulling from sit-to-stand and assisted standing, skills that contribute to the onset of independent locomotion. The throw-baby-throw technology specifically targets the physical skill of reaching. These aspects of the technologies emphasize the body structure and function domain by encouraging the advancement of specific physical skills.

The sit-to-stand and throw-baby-throw technologies presented in this technical report simultaneously embrace the medical and social models of disability. The ICF represents an attempt to find balance between dominant disability models. In certain academic or advocacy circles, there is a broader, on-going societal conversation regarding different ways of thinking about 


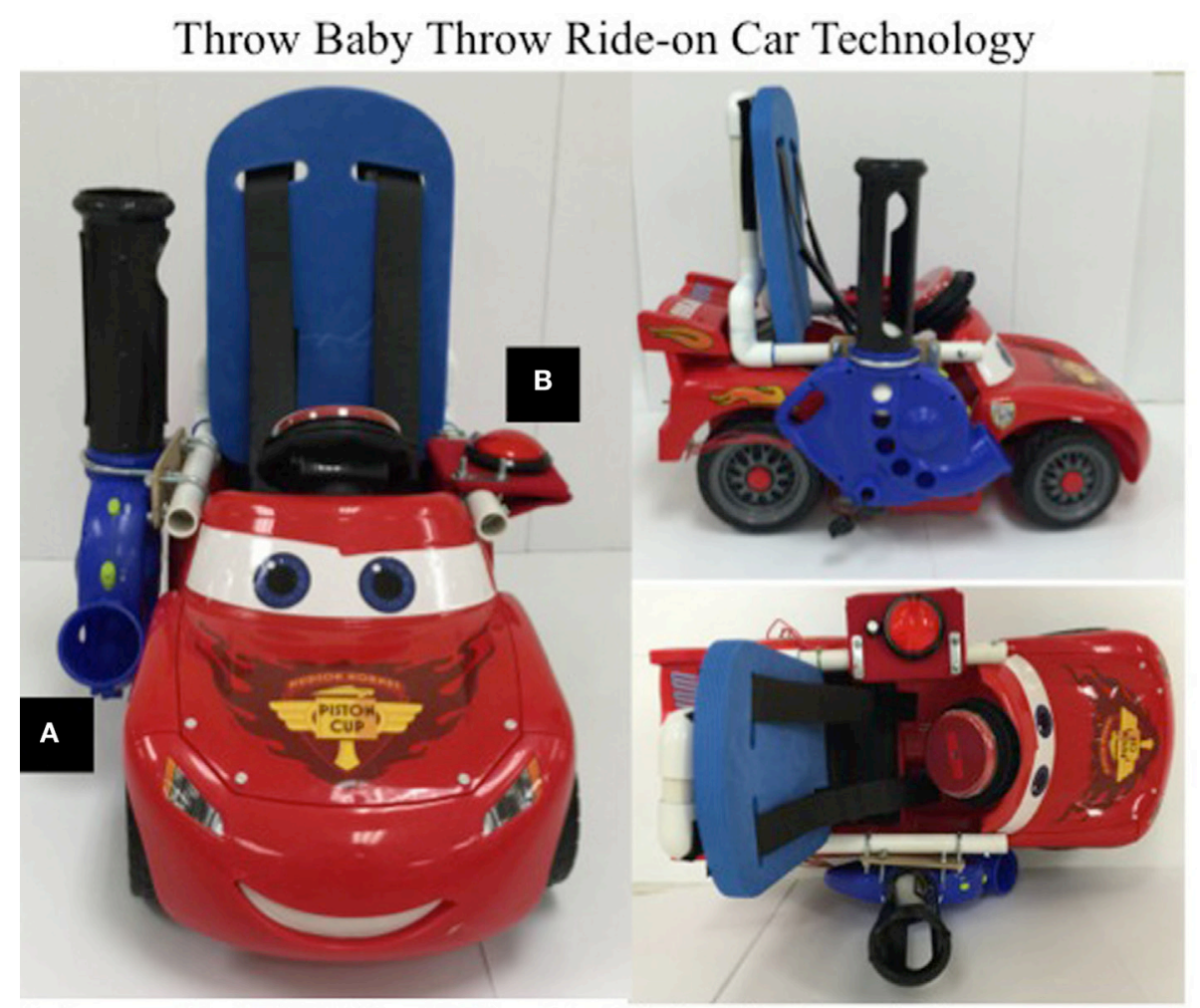

FIGURE 7 | (A) Fisher-Price@ Triple Hit Baseball toy-pitching machine; (B) Adafruit@ arcade button and potentiometer installed on a custom wood panel mounting system.

disability. However, knowledge of disability models themselves, and their implications, has yet to be translated into most of the lay-public's daily community life. Disability models are sets of beliefs about the cause, nature, and treatment of disability. The medical model views disability as an individual pathology that is determined through diagnostic criteria based on deviation from a statistically determined norm for the purpose of treatment or cure (Olkin, 2002). An alternative view is the social model of disability. In this model, the "problem" of disability is primarily socially constructed and society's lack of accommodation for people's differences is the cause of the disabling experience (Olkin, 2002). Therefore, while impairment may exist at an individual level, disability occurs because societies are structured under the assumption that everyone is healthy, without disability, and fits a culturally constructed norm or ideal (Wendell, 1996). The social model encourages the formation of an identity inclusive of disability as a positive experience, akin to a minority group, one that can help to improve an individual's quality of life and adaptability (Dunn and Burcaw, 2013; Bogart, 2014).

Both technologies presented in this technical report emphasize impairments at the individual level by advancing physical skills. These aspects of the technologies align more closely with the medical model. However, encouragement of physical skills is embedded within ride-on cars, a daily play, and exploration and participation experience of millions of children without disabilities. Both technologies provide a means for children with disabilities to engage in similar childhood experiences. The low-cost, low-tech, and do-it-yourself aspects of the technologies promotes increased access for children with disabilities and supports inclusion and full participation in society. These aspects of the technologies align more closely with the social model. Both technologies embrace that treatment and rehabilitation are important while simultaneously creating an interface in the form of modified ride-on cars between children with disabilities and their environment as a means to reduce barriers and support social participation. Perhaps the social model of disability needs even further influence in rehabilitative practices surrounding self-directed mobility. Although commonly cited as at odds with rehabilitation frameworks, the ICF incorporates psychological and social (environmental) factors of the social model, and provides a framework to engage these models in a complimentary way as demonstrated in the current technical report (Wiart and Darrah, 2002; Gibson et al., 2009; Gibson and Teachman, 2012; McKeever et al., 2013).

There is a growing alternative culture within pediatric rehabilitation that highlights a social model of disability and embraces "effective mobility," defined as "locomotion that is functional, timely and energy-efficient" (Butler, 2009, p. 5). Effective mobility emphasizes a multi-modal view, suggesting that individuals, including young children, may need several options for 
locomotion to provide opportunities for participation in daily life depending upon the environment and situation (Feldner et al., 2016). The multi-modal view of self-directed mobility more closely aligns with the social model of disability because it does not view a lack of independent locomotion as a disability, but rather embraces alternative ways that society may accommodate for people's differences by supporting access to powered mobility devices.

\section{CONCLUSION}

As a practical application of the shift in thinking to effective mobility, pediatric rehabilitation professionals can engage in more value-neutral modes of caregiver education, describing the benefits of self-directed mobility at all levels, whether generated via activation of a child's own body or via a mobility device, and emphasizing that both modes should occur as early as possible. Adjustments in service delivery can also include an explicit commitment to a paradigm of "right mode, right time" decision-making, in which all modes of self-directed mobility are considered equally valuable, dependent on environmental contexts and needs of the child. Doing so further reinforces the value of multi-modal self-directed mobility, and weakens a walking vs. wheelchair dichotomization by considering other forms of locomotion like bicycles, ride-on toys, the Segway, go-carts, and scooters (Feldner et al., 2016). Moreover, a team approach should be utilized to ensure that the child himself or herself is at the

\section{REFERENCES}

Anderson, D. I., Campos, J. J., Witherington, D. C., Dahl, A., Rivera, M., He, M., et al. (2013). The role of locomotion in psychological development. Front. Psychol. 4:440. doi:10.3389/fpsyg.2013.00440

Bogart, K. R. (2014). The role of disability self-concept in adaptation to congenital or acquired disability. Rehabil. Psychol. 59, 107-115. doi:10.1037/a0035800

Bottos, M., and Gericke, C. (2003). Ambulatory capacity in cerebral palsy: prognostic criteria and consequences for intervention. Dev. Med. Child Neurol. 45, 786-790. doi:10.1017/S0012162203001452

Butler, C. (2009). Effective Mobility for Children with Motor Disabilities. Available at: http://www.global-help.org/publications/books/help_effectivemobility.pdf

Butler, C., Okamoto, G. A., and McKay, T. M. (1983). Powered mobility for very young disabled children. Dev. Med. Child Neurol. 25, 472-474. doi:10.1111/ j.1469-8749.1983.tb13792.x

Campos, J. J., Anderson, D. I., Barbu-Roth, M. A., Hubbard, E. M., Hertenstein, M. J., and Withering, D. (2000). Travel broadens the mind. Infancy 1, 149-219. doi:10.1207/S15327078IN0102_1

Carter, E. W., Sisco, L. G., Chung, Y. C., and Stanton-Chapman, T. L. (2010). Peer interactions of students with intellectual disabilities and/or autism: a map of the intervention literature. Res. Pract. Persons Sev. Disabil. 35, 63-79. doi:10.2511/ rpsd.35.3-4.63

Chiulli, C., Corradi-Scalise, D., and Donatelli-Schultheiss, L. (1988). Powered mobility vehicles as aids in independent locomotion for young children. Suggestion from the field. Phys. Ther. 68, 997-999.

Clark, J. E., and Metcalfe, J. S. (2002). "The mountain of motor development: a metaphor," in Motor development: Research and review, Vol. 2. eds J. E. Clark, and J. H. Humphrey (Reston, VA: National Association for Sport and Physical Education), 62-95.

Cooper, R., Gottlieb, P., and Koeff, B. (1992). "A new low-cost approach to early powered mobility - the Coopercar," in Proceedings of the Johns Hopkins Search for Computing Applications to Assist Persons with Disabilities, Laurel, MD, $146-148$. center of these modal decision-making processes, at the earliest possible opportunity.

\section{AUTHOR NOTES}

There are currently no plans to pursue commercialization of either technology presented in this report. It is critical that any electrical and structural modifications to a ride-on car or toy-based pitching machine be fully tested and checked by an engineer with the appropriate expertise to determine safety. The technologies described in this report may or may not be appropriate for any individual child. It is important that families work with their child's clinical team in order to reach appropriate decisions of treatment on an individual basis.

\section{AUTHOR CONTRIBUTIONS}

SL, JG, WS, HF, and KB created the idea and were significantly involved in writing and reviewing manuscript drafts. BG, SR, $\mathrm{MC}, \mathrm{AW}$, and $\mathrm{ZS}$ were involved in the design, prototyping, and testing of the technologies, as well as reviewing manuscript drafts.

\section{FUNDING}

SL and JCG were supported by NIH NICHD NCMRR AWARD 5R21HD078708 (PI JCG). JCG was supported by NSF AWARD 1252876 (PI JCG).

Cooper, R. A., Tolerico, M., Kaminski, B. A., Spaeth, D., Ding, D., and Cooper, R. (2008). Quantifying wheelchair activity of children: a pilot study. Am. J. Phys. Med. Rehabil. 87, 977-983. doi:10.1097/PHM.0b013e31818dfe74

Daudji, A., Eby, S., Foo, T., Ladak, F., Sinclair, C., Landry, M. D., et al. (2011). Perceptions of disability among south Asian immigrant mothers of children with disabilities in Canada: implications for rehabilitation service delivery. Disabil. Rehabil. 33, 511-521. doi:10.3109/09638288.2010.498549

Dunn, D. S., and Burcaw, S. (2013). Disability identity: exploring narrative accounts of disability. Rehabil. Psychol. 58, 148-157. doi:10.1037/a0031691

Feldner, H. A., Logan, S. W., and Galloway, J. C. (2016). Why the time is right for a radical paradigm shift in early power mobility: the role of mobility technology devices, policy, and stakeholders. Disabil. Rehabil. Assist. Technol. 11, 89-102. doi:10.3109/17483107.2015.1079651

Fidler,D.J. (2005). TheemergingDownsyndromebehavioralphenotypeinearlychildhood. Infants Young Child. 18, 86-103. doi:10.1097/00001163-200504000-00003

Galloway, J. C., Ryu, J. C., and Agrawal, S. K. (2008). Babies driving robots: self-generated mobility in very young infants. J. Intell. Serv. Rob. 1, 123-134. doi:10.1007/s11370-007-0011-2

Gibson, B., Darrah, J., Cameron, D., Hashemi, G., Kingsnorth, S., Lepage, C., et al. (2009). Revisiting therapy assumptions in children's rehabilitation: clinical and research implications. Disabil. Rehabil. 31, 1446-1453. doi:10.1080/09638280802621390

Gibson, B. E., Carnevale, F. A., and King, G. (2012). 'This is my way': reimagining disability, independence and interconnectedness of persons and assistive technologies. Disabil. Rehabil. 34, 1894-1899. doi:10.3109/09638288.2012. 670040

Gibson, B. E., and Teachman, G. (2012). Critical approaches in physical therapy research: investigating the symbolic value of walking. Physiother. Theory Pract. 28, 474-484. doi:10.3109/09593985.2012.676936

Gibson, B. E., Teachman, G., Wright, V., Fehlings, D., Young, N. L., and McKeever, P. (2011). Children's and parents' beliefs regarding the value of walking: rehabilitation implications for children with cerebral palsy. Child Care Health Dev. 38, 61-69. doi:10.1111/j.1365-2214.2011.01271.x 
Haywood, K. M., and Getchell, N. (2009). Lifespan Motor Development, 5th Edn. Champaign, IL: Human Kinetics.

Held, R., and Hein, A. (1963). Movement-produced stimulation in the development of visually guided behavior. J. Comp. Physiol. Psychol. 56, 872-876. doi:10.1037/ h0040546

Huang, H., and Galloway, J. C. (2012). Modified ride-on toy cars for early power mobility: a technical report. Pediatr. Phys. Ther. 24, 149-154. doi:10.1097/ PEP.0b013e31824d73f9

Jones, M. A., McEwen, I. R., and Neas, B. R. (2012). Effects of power wheelchairs on the development and function of young children with severe motor impairments. Pediatr. Phys. Ther. 24, 131-140. doi:10.1097/PEP.0b013e31824c5fdc

Law, M., Darrah, J., Pollock, N., Rosenbaum, P., Russell, D., Walter, S. D., et al. (2007). Focus on function - a randomized control trial comparing two rehabilitation interventions for young children with cerebral palsey. BMC Pediatr. 7. doi:10.1186/1471-2431-7-31

Libertus, K., and Needham, A. (2010). Teach to reach: the effects of active vs. passive reaching experiences on action and perception. Vision Res. 50, 2750-2757. doi:10.1016/j.visres.2010.09.001

Livingstone, R. (2010). A critical review of powered mobility assessment and training for children. Disabil. Rehabil. Assist. Technol. 5, 392-400. doi:10.3109/ 17483107.2010.496097

Lobo, M. A., Harbourne, R. T., Dusing, S. C., and McCoy, S. W. (2013). Grounding early intervention: physical therapy cannot just be about motor skills anymore. Phys. Ther. 93, 94-103. doi:10.2522/ptj.20120158

Logan, S. W., Feldner, H. A., Galloway, J. C., and Huang, H. H. (2016). Modified ride-on car use by children with complex medical needs. Pediatr. Phys. Ther. 28, 100-107. doi:10.1097/PEP.0000000000000210

Logan, S. W., Feldner, H. A., Lobo, M. A., Winden, H. N., MacDonald, M., and Galloway, J. C. (2017). Power, up: exploration and play in a novel modified ride-on car for standing. Pediatr. Phys. Ther. 29, 30-37. doi:10.1097/ PEP.0000000000000336

Logan, S. W., Huang, H. H., Stahlin, K., and Galloway, J. C. (2014). Modified ride-on car use for mobility and socialization: single-case study of an infant with Down syndrome. Pediatr. Phys. Ther. 26, 418-426. doi:10.1097/PEP.0000000000000070

Logan, S. W., Robinson, L. E., Wilson, A. E., and Lucas, W. A. (2011). Getting the fundamentals of movement: a meta-analysis of the effectiveness of motor skill interventions in children. Child Care Health Dev. 38, 305-315. doi:10.1111/j.1365-2214.2011.01307.x

Lynch, A., Ryu, J., Agrawal, S., and Galloway, J. C. (2009). Power mobility training for a 7-month-old infant with spina bifida. Pediatr. Phys. Ther. 21, 362-368. doi:10.1097/PEP.0b013e3181bfae4c

McKeever, P., Rossen, B. E., Scott, H., Robinson-Vincent, K., and Wright, V. (2013). The significance of uprightness: parents' reflections on children's responses to a hands-free walker for children. Disabil. Soc. 28, 380-392. doi:10.1080/ 09687599.2012.714259

Nicholson, J., and Bonsall, M. (2002). Powered mobility for children under five years of age in England. Br. J. Occup. Ther. 65, 291-293. doi:10.1177/ 030802260206500608

Olkin, R. (2002). Could you hold the door for me? Including disability in diversity. Cultur. Divers. Ethnic Minor. Psychol. 8, 130-137. doi:10.1037/1099-9809.8.2.130

Ostensjø, S., Carlberg, E. B., and Vøllestad, N. K. (2005). The use and impact of assistive devices and other environmental modifications on everyday activities and care in young children with cerebral palsy. Disabil. Rehabil. 27, 849-861. doi:10.1080/09638280400018619

Ragonesi, C. B., Chen, X., Agrawal, S., and Galloway, J. C. (2010). Power mobility and socialization in preschool: a case study of a child with cerebral palsy. Pediatr. Phys. Ther. 22, 322-329. doi:10.1097/PEP.0b013e3181eab240

Robinson, L. E., Stodden, D. F., Barnett, L. M., Lopes, V. P., Logan, S. W., D’Hondt, E., et al. (2015). Motor competence and its effect on positive developmental trajectories of health. Sports Med. 45, 1273-1284. doi:10.1007/s40279-015-0351-6
Rosen, L., Roos, J., Sabet, A., Vander Schaaf, P., Wonsettler, T., Arva, J., et al. (2009). RESNA position on the application of power wheelchairs for pediatric users. Assist. Technol. 21, 218. doi:10.1080/10400430903246076

Schoenmakers, M. A., Uiterwaal, C. S., Gulmans, V. A., Gooskens, R. H., and Helders, P. J. (2005). Determinants of functional independence and quality of life in children with spina bifida. Clin. Rehabil. 19, 677-685. doi:10.1191/ $0269215505 \mathrm{cr} 865 \mathrm{oa}$

Smith, L. B., and Gasser, M. (2005). The development of embodied cognition: six lessons from babies. Artif. Life 11, 13-30. doi:10.1162/1064546053278973

Staincliffe, S. (2003). Wheelchair services and providers: discriminating against disabled children? Br. J. Ther. Rehabil. 10, 151-159. doi:10.12968/bjtr.2003.10. 4.13555

Thelen, E., Schoner, G., Scheier, C., and Smith, L. B. (2001). The dynamics of embodiment: a field theory on infant preservative reaching. Behav. Brain Sci. 24, 1-86. doi:10.1017/S0140525X01003910

Thelen, E., and Smith, L. B. (1994). A Dynamic Systems Approach to the Development of Cognition and Action. Cambridge, MA: MIT Press.

Tudella, E., Pereira, K., Basso, R. P., and Svelsbergh, G. J. P. (2011). Description of the motor development of 3-12 month old infants with Down syndrome: the influence of the postural body position. Res. Dev. Disabil. 32, 1514-1520. doi:10.1016/j.ridd.2011.01.046

Uchiyama, I., Campos, J. J., Frankel, C. B., Anderson, D. I., Witherington, D., Lejeune, L., et al. (2008). Locomotor experience affects self and emotion. Dev. Psychol. 44, 1225-1231. doi:10.1037/a0013224

Ulrich, D. A., Ulrich, B. D., Angulo-Kinzler, R. M., and Yun, J. (2001). Treadmill training of infants with Down syndrome: evidence-based developmental outcomes. Pediatrics 108, E84. doi:10.1542/peds.108.5.e84

Webster, A. A., and Carter, M. (2007). Social relationships and friendships of children with developmental disabilities: implications for inclusive settings. A systematic review. J. Intellect. Dev. Disabil. 32, 200-213. doi:10.1080/13668250701549443

Wendell, S. (1996). The Rejected Body: Feminist Philosophical Reflections on Disability. New York, NY: Psychology Press.

Wiart, L., and Darrah, J. (2002). Changing philosophical perspectives on the management of children with physical disabilities - their effect on the use of powered mobility. Disabil. Rehabil. 24, 492-498. doi:10.1080/09638280110105240

Wiart, L., Darrah, J., Hollis, V., Cook, A., and May, L. (2004). Mothers' perceptions of their children's use of powered mobility. Phys. Occup. Ther. Pediatr. 24, 3-21. doi:10.1300/J006v24n04_02

Wu, J., Looper, J., Ulrich, D. A., and Angulo-Barroso, R. M. (2010). Effects of various treadmill interventions on the development of joint kinematics in infants with Down syndrome. Phys. Ther. 90, 1265-1276. doi:10.2522/ptj. 20090281

Wuang, Y. P., Wang, C. C., Huang, M. H., and Su, C. Y. (2008). Profiles and cognitive predictors of motor functions among early school-age children with mild intellectual disabilities. J. Intellect. Disabil. Res. 52, 1048-1060. doi:10.1111/j.1365-2788.2008.01096.x

World Health Organization. (2001). International Classification of Functioning, Disability, and Health. Geneva: WHO.

Conflict of Interest Statement: The authors declare that the research was conducted in the absence of any commercial or financial relationships that could be construed as a potential conflict of interest.

Copyright $\odot 2017$ Logan, Feldner, Bogart, Goodwin, Ross, Catena, Whitesell, Sefton, Smart and Galloway. This is an open-access article distributed under the terms of the Creative Commons Attribution License (CC BY). The use, distribution or reproduction in other forums is permitted, provided the original author(s) or licensor are credited and that the original publication in this journal is cited, in accordance with accepted academic practice. No use, distribution or reproduction is permitted which does not comply with these terms. 